\title{
CARACTERIZAÇÃO, CLASSIFICAÇÃO E ANÁLISE QUALITATIVA E QUANTITATIVA DOS RESÍDUOS DE CONSTRUÇÃO CIVIL EM RESIDÊNCIAS PADRÃO NORMAL EM BAIRROS NOVOS DA CIDADE DE CAMPINAS (SP). CHARACTERIZATION, CLASSIFICATION AND QUALITATIVE AND QUANTITATIVE ANALYSIS OF WASTE OF CIVIL CONSTRUCTION IN NORMAL STANDARD RESIDENCIES IN NEW DISTRICTS OF THE CITY OF CAMPINAS (SP).
}

CARVALHO, Renan Henrique; CAMARGO, Renato Franco Universidade São Francisco, campus Campinas, unidade Swift renanhcarvalho@bol.com.br

RESUMO. A indústria da construção civil, entendida como um setor com elevada importância econômica, assume um papel fundamental para o desenvolvimento de um país. Este trabalho analisa de forma qualitativa e quantitativa os resíduos gerados em obras residenciais na cidade de Campinas. Primeiro é apresentado a contextualização e a classificação dos Resíduos da Construção Civil (RCC), de acordo com a norma técnica e em seguida algumas alternativas de reciclagem e reutilização dos mesmos. $\mathrm{O}$ estudo é baseado no acompanhamento de três obras residenciais desde as etapas iniciais de fundação até a parte de acabamento. Analisando de forma local, é possível aos poucos diminuir os impactos que o ramo da construção civil vem causando ao planeta. Esse trabalho é um estudo descritivo que abrange aspectos gerais e amplos que reflete um contexto social. Tem uma abordagem qualitativa, cujo objetivo é analisar os resíduos sólidos da construção e demolição, advindos de construções de padrão normal. Para a coleta de dados e observações dos fatos, a pesquisa se classifica como de campo, possibilitando o estabelecimento de relações constates entre as condições pré-determinadas. A coleta de dados foi feita nas visitações aos locais como fontes primárias e em pesquisas na internet como fontes secundárias, buscando sempre o maior aproveitamento para um melhor resultado final. Para análise dos resultados, foi elaborado uma tabela para cada uma das obras, na qual foram alimentadas após todas as visitas feitas com o resíduo encontrado no local, através da porcentagem dele comparado ao total de RCC naquele dia.

Palavras-chave: resíduos da construção, reciclagem, reutilização.

ABSTRACT. The construction industry, understood as a sector with high economic importance, plays a key role in the development of a country. This work analyzes qualitatively and quantitatively the residues generated in residential works in Campinas. First, the contextualisation and classification of Civil Construction Waste (CCW) is presented, according to the technical standard and then some alternatives of recycling and reuse then. The study is based on the follow-up of three residential works from the initial stages of foundation to the finishing part. Analyzing locally, it is possible to gradually reduce the impacts that the construction industry has been causing to the planet. This work is a descriptive study that covers general and broad aspects that reflects a social context (OLIVEIRA 1999). It has a qualitative approach, whose objective is to analyze the solid residues of the construction and demolition, coming from constructions of normal standard. For the collection of data and observations of the facts, the research is classified as field, researching it possible to establish relations between the pre-determined conditions. The data 
collection was done in the visits to the sites as primary sources and in researches in the internet as secondary sources, always seeking the greater use for a better final result. To analyze the results, a table was prepared for each of the works, in which they were fed after all the visits made with the residue found in the place, by the percentage of it compared to the total RCC on that day.

Keywords: construction waste, recycling, reuse.

\section{INTRODUÇÃO}

A construção civil se destaca como um setor muito significativo na economia de um país, recebe altíssimos investimentos e gera empregos a todo o momento. O mundo está em constante adaptação e para isso necessita que a engenharia civil trabalhe para acompanhar tantas mudanças, como tornar ambientes acessíveis a todos, planejar vias de trânsito que comportem o volume atual de automóveis, desenvolver construções adaptadas a aguentar qualquer tipo de fenômeno da natureza, dentre outros avanços que são extremamente necessários para os dias de hoje.

Os resíduos da construção civil são provenientes de construção, demolição, reformas, reparos e da preparação e escavação do solo, e geram impactos com resíduos sólidos, químicos, líquidos e sonoros, a saber, na ocupação do terreno, poluem e contaminam o solo, na contaminação de pessoas e do solo, comprometem a disponibilidade de água, esgotam o recurso natural, na poluição atmosférica, efeito estufa, destruição da camada de ozônio, na destinação de efluentes líquidos e, danos ao meio ambiente (SANTOS e SOARES NETO, 2008; PINHEIRO, 2006).

A demanda por sustentabilidade dentro das construções civis proporcionou melhorias no desempenho ambiental das edificações e seus sistemas de avaliação (ROCHA, 2012; GORON, 2010; LARSSON, 2004). Os sistemas de avaliação podem ser orientados para o mercado ou para a pesquisa (CSILLAG, 2007; SELIH, 2007).

Ainda que o RCD não seja considerado como resíduo de alta periculosidade existem muitos outros materiais que acabam sendo tóxicos, favorecem a proliferação de doenças por causa de acúmulo de água e, devido ao grande volume desse tipo de lixo a aparência e a qualidade do ambiente urbano fica comprometida (IPEA, 2012). Segundo a resolução $n^{\circ}$ 307/2002 CONAMA (2002, p. 572-574) os resíduos se classificam em quatro classes de acordo com sua característica:

- Classe A - são os resíduos reutilizáveis ou recicláveis como agregados, tais como: componentes cerâmicos (tijolos, blocos, telhas, placas de revestimento etc.), argamassa e concreto e peças pré-moldadas em concreto (blocos, tubos, meios-fios etc.);

- Classe B - são os resíduos recicláveis para outras destinações, tais como: plásticos, papel, papelão, metais, vidros, madeiras e gesso;

- Classe C - são os resíduos para os quais não foram desenvolvidas tecnologias ou aplicações economicamente viáveis que permitam a sua reciclagem ou recuperação;

- Classe D: são resíduos perigosos oriundos do processo de construção, tais como tintas, solventes, óleos e outros ou aqueles contaminados ou prejudiciais à saúde.

Uma das propostas é a Estratégia Nacional para o Desenvolvimento Sustentável a qual propõe o desenvolvimento de uma política de habitação sustentável segundo quatro vetores: durabilidade dos materiais de construção; flexibilidade de adaptação à ocupação ao longo do tempo; coesão social para garantir o acesso ao mercado da habitação por famílias mais 
necessitadas; e, eficiência ecológica através do uso racional do solo, de materiais, de energia e de água (KIBERT, 2008; PINHEIRO, 2006; KIBERT, 1994).

A importância do presente projeto recai no diagnóstico da a situação atual da construção civil na cidade de Campinas (SP), pois investigará a geração de resíduos em obras de casas de padrão normal em bairros recém-criados, tecendo comparações às legislações vigentes. Este levantamento trará como benefícios aos discentes o desenvolvimento e aperfeiçoamento teórico e constatação das práticas recorrentes quanto ao gerenciamento dos resíduos na cidade de Campinas (SP).

Resíduo da Construção e Demolição (RCD) ou Resíduo da Construção Civil (RCC) é todo resíduo gerado no processo construtivo, de reforma, escavação ou demolição. Popularmente conhecido como entulho, esses resíduos são compostos de fragmentos ou restos de tijolo, concreto, argamassa, aço, madeira, etc. (ABRECON, 2015).

Atualmente, a construção civil é o setor que mais polui, sendo responsável pelo consumo de $40 \%$ a $75 \%$ da matéria-prima produzida no planeta. Para cada ser humano são produzidos 500 quilos de entulho, o que equivale a 3,5 milhões de toneladas por ano (AGOPYAN, 2013). E esses dados tendem a aumentar, pois a população está aumentando e a demanda do setor cresce cada dia mais.

O Brasil, que hoje é classificado como país emergente, tem crescido bastante na indústria civil, resultando em um elevado índice de desperdício de materiais. Segundo Koz (2013) a indústria da construção civil no país gasta muito mais do que Estados Unidos e Europa. As obras de demolição e reforma são maiores que as de construção e em consequência geram um maior número de resíduos (SANTOS, 2008).

Atualmente, a construção civil é o setor que mais polui, sendo responsável pelo consumo de $40 \%$ a $75 \%$ da matéria-prima produzida no planeta. Para cada ser humano são produzidos 500 quilos de entulho, o que equivale a 3,5 milhões de toneladas por ano (AGOPYAN, 2013). E esses dados tendem a aumentar, pois a população está aumentando e a demanda do setor cresce cada dia mais. A figura 1 ilustra os processos que os materiais utilizados na construção civil passam ao longo de sua vida útil.

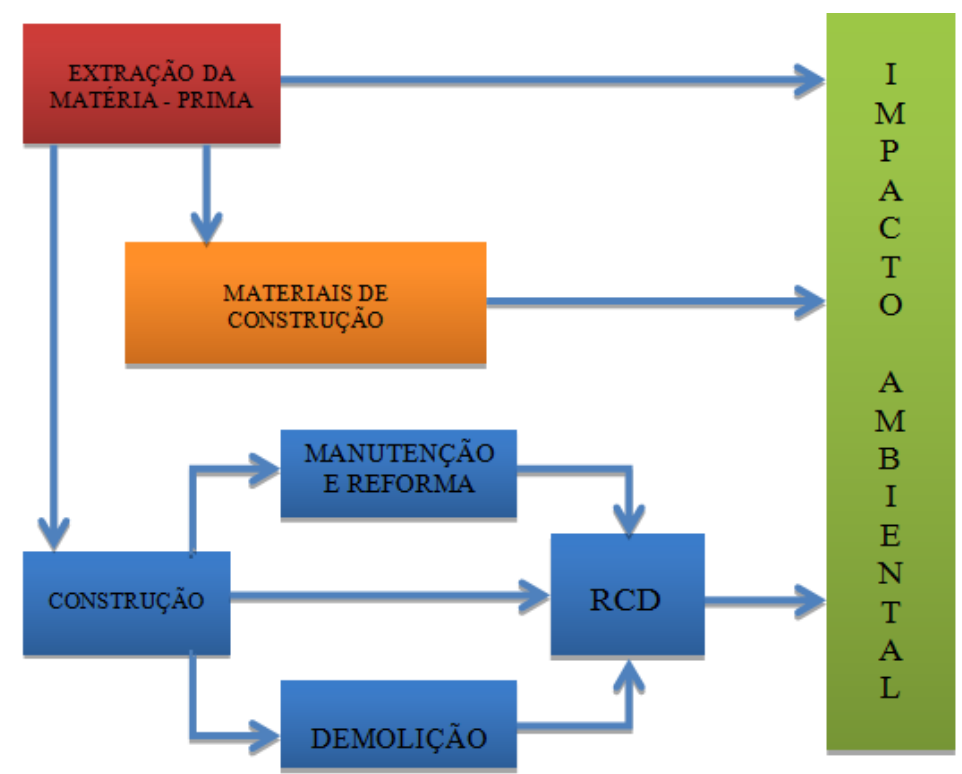

Figura 1 - Cadeia da construção civil (Fonte: RENAN CARVALHO (2016); Adaptado de PUT apud SCHNEIDER (2003, p.46)) 
A geração de resíduos também é influenciada pela forma como se constroem as edificações e como se faz a gestão dos Resíduos de Construção e Demolição sendo que 10\% dos materiais utilizados na obra acabam virando resíduos (OLIVEIRA et al., 2008). A tabela 1 mostra os principais materiais que são desperdiçados por causa de uma gestão ineficiente de obras por todo o país.

Tabela 1 - Taxa de desperdício de materiais de construção no Brasil (Fonte: RENAN CARVALHO (2016); Adaptado de ESPINELLI; 2005)

\begin{tabular}{cccc}
\hline \multicolumn{4}{c}{ Taxa de desperdício \% } \\
\hline Material & Média & Mínima & Máxima \\
\hline Concreto usinado & 9 & 2 & 23 \\
Aço & 11 & 4 & 16 \\
Blocos e tijolos & 13 & 3 & 48 \\
Placas cerâmicas & 14 & 2 & 50 \\
Revestimento têxtil & 14 & 14 & 14 \\
Eletrodutos & 15 & 13 & 18 \\
Tubos & 15 & 13 & 18 \\
Tintas & 17 & 8 & 56 \\
Fios & 27 & 14 & 35 \\
Gesso & 30 & 14 & 120 \\
\hline
\end{tabular}

A região metropolitana de Campinas (RMC) é composta por 19 municípios conforme demonstrado na figura 3, dentre os quais Campinas é a cidade mais rica, sendo considerado um centro econômico, industrial, científico e tecnológico do Estado de São Paulo (PGIRS, 2012). Segundo dados do IBGE, o município, no ano de 2009 possuía um PIB de $\mathrm{R} \$ 31.654 .719$ sendo um dos maiores do país.

A maior parte das residências na cidade de Campinas se enquadram na classificação de padrão normal segundo a NBR 12.721 tendo uma área total de terreno de até $106,44 \mathrm{~m}^{2}$,

Como consequência da riqueza e da grande produção, a cidade de Campinas gera um grande volume de resíduo diariamente. São 4.410 toneladas de resíduos sólidos gerados todos os dias na cidade de diversas fontes e com várias características físicas, químicas e biológicas sendo que muitos apresentam algum nível de periculosidade.

\section{Sustentabilidade na construção civil}

O uso desenfreado dos recursos naturais pelo homem causou um grande impacto no meio ambiente. Durante muito tempo o planeta foi explorado por todos os setores de produção, ao mesmo tempo que resíduos foram gerados e descartados de forma errada na natureza sem nenhuma preocupação ou cuidado. Atualmente é possível ver os impactos causados por cauda disso, como por exemplo, o aquecimento global, el ninhos, destruição dos solos, extinção de espécies da fauna e da flora, dentre outras consequências que o ser humano hoje, tenta reverter ou frear.

Dar um fim adequado para o RCD é extremamente importante para as empresas do ramo da construção civil. Muito do que é gerado é descartado em aterros e não são usados novamente, porém, boa parte dos resíduos podem ter uma nova utilidade se forem reciclados corretamente. Essa é uma forma de ajudar o meio ambiente e até mesmo diminuir o custo de uma obra. 
Comparativamente a países do primeiro mundo, a reciclagem de resíduos no Brasil como materiais de construção é ainda tímida, com a possível exceção da intensa reciclagem praticada pelas indústrias de cimento e de aço (Ângulo et al 2010). Uma vez que a discussão sobre esse tema se tornou o foco do país recentemente.

Diante da exorbitante quantidade de resíduos gerados no país, existem normas regulamentadores que classificam os resíduos e determinam sua classificação. A resolução 307/2002 - CONAMA foi criada com o intuito de facilitar o gerenciamento dos resíduos derivados da construção civil. A tabela 2 a seguir mostra essas classificações.

Tabela 2 - Classificação dos RCD (Fonte: RENAN CARVALHO (2016); Adaptado da resolução 307/2002 - CONAMA)

\begin{tabular}{|c|c|c|c|}
\hline Tipos de RCD & Definição & Exemplos & Destinação \\
\hline Classe A & $\begin{array}{l}\text { São os resíduos reutilizáveis ou } \\
\text { recicláveis como agregados }\end{array}$ & $\begin{array}{l}\text { - Provenientes de pavimentação e de } \\
\text { outras obras de infra-estrutura, inclusive } \\
\text { solos provenientes de terraplanagem; } \\
\text { - Provenientes de edificações: } \\
\text { componentes cerâmicos (tijolos,blocos, } \\
\text { telhas, placas de revestimento etc.), } \\
\text { argamassa e concreto; } \\
\text { - Provenientes de processo de fabricação } \\
\text { e/ou demolição de peças pré-moldadas } \\
\text { em concreto (blocos, tubos, meio-fios } \\
\text { etc.) produzidas nos canteiros de obras; }\end{array}$ & $\begin{array}{l}\text { Deverão ser reutilizados ou } \\
\text { reciclados na forma de } \\
\text { agregados ou encaminhados a } \\
\text { aterro de resíduos classe A de } \\
\text { reservação de material para } \\
\text { usos futuros; }\end{array}$ \\
\hline Classe B & $\begin{array}{c}\text { São os resíduos recicláveis para } \\
\text { outras destinações }\end{array}$ & $\begin{array}{l}\text { Plásticos, papel, papelão, metais, vidros, } \\
\text { madeiras e gesso; }\end{array}$ & $\begin{array}{l}\text { Deverão ser reutilizados, } \\
\text { reciclados ou encaminhados a } \\
\text { áreas de armazenamento } \\
\text { temporário, } \\
\text { sendo dispostos de modo a } \\
\text { permitir a sua utilização ou } \\
\text { reciclagem futura; }\end{array}$ \\
\hline Classe C & $\begin{array}{l}\text { São os resíduos para os quais } \\
\text { não foram desenvolvidas } \\
\text { tecnologias ou aplicações } \\
\text { economicamente viáveis que } \\
\text { permitam a sua reciclagem ou } \\
\text { recuperação }\end{array}$ & Produtos oriundos do gesso & $\begin{array}{l}\text { Deverão ser armazenados, } \\
\text { transportados e destinados em } \\
\text { conformidade com as normas } \\
\text { técnicas específicas; }\end{array}$ \\
\hline Classe D & $\begin{array}{l}\text { São resíduos perigosos oriundos } \\
\text { do processo de construção }\end{array}$ & $\begin{array}{c}\text { Tintas, solventes, óleos e outros ou } \\
\text { aqueles contaminados ou prejudiciais à } \\
\text { saúde oriundos de demolições, reformas e } \\
\text { reparos de clínicas radiológicas, } \\
\text { instalações industriais e outros, bem como } \\
\text { telhas e demais objetos e materiais que } \\
\text { contenham amianto ou outros produtos } \\
\text { nocivos à saúde. }\end{array}$ & $\begin{array}{l}\text { Deverão ser armazenados, } \\
\text { transportados e destinados em } \\
\text { conformidade com as normas } \\
\text { técnicas específicas. }\end{array}$ \\
\hline
\end{tabular}

É importante salientar a importância de um bom planejamento do projeto. O engenheiro ou arquiteto do projeto deve sempre se preocupar com o sistema construtivo a ser adotado, tipos de matérias que serão usados, ser assertivo em seus cálculos e dimensionamento e até mesmo pensar em formar de aproveitar materiais em projetos completares, sempre visando a não geração de resíduos (LIMA, 2012). Se a obra for 
gerenciada da maneira correta, muitos gastos desnecessários serão evitados em compras excessivas de matérias e consequentemente os RCD's serão menores.

Existem diversas maneiras de reutilizar e reciclar o RCC. Muitas vezes tal ato acaba trazendo uma economia para a obra, uma vez que os materiais já usados podem assumir outra funcionalidade e substituir matérias que serão compradas. É necessária uma análise de todo o processo para que a economia seja máxima, diminuindo o valor final da obra e ao mesmo tempo contribuindo com o meio ambiente.

Em 2003, o município de Campinas implantou em local público a Unidade Recicladora de Materiais - URM com capacidade 70 t/hora de resíduo, visando o beneficiamento e tratamento dos Resíduos de Construção Civil - RDCC (PGIRS, 2012). Essa unidade é gerenciada pelo Departamento de Limpeza Urbana - DLU, que é responsável pela organização das atividades realizadas no local de atender a legislação.

Em conjunto com a URM, existe uma cooperativa (Cooperativa Tatuapé) que realiza legalmente a segregação e comercialização dos resíduos recicláveis que entram na unidade visando o seu reaproveitamento (PGIRS, 2012). O Sistema de Gestão Integrada dos Resíduos Sólidos em Campinas estabelece normas para os geradores, o transporte, a destinação, recepção e captação de resíduos de construção civil. E para aqueles que não as cumprir está sujeito a penalidades.

Existe também na cidade, ecopontos e Pontos verdes para a destinação voluntária, por parte da população, dos resíduos gerados na construção. Esses pontos visam ajudar a as cooperativas a atender a alta demanda e ao mesmo tempo dar a destinação correta a esse tipo de resíduo. Esse método tem se mostrado bastante eficaz, dados mostram que foram retirados aproximadamente uma média de 648,00 ton/mês só de resíduos de construção civil e galharias destes locais (PGIRS, 2012).

Diante do cenário exposto, este projeto tem como objetivo diagnosticar a gestão de Resíduos de Construção e Demolição (RCD) em obras de residência padrão normal, segundo a NBR no 12.721-2004, em novos bairros da cidade de Campinas.

Os objetivos específicos são:

- Mapear bairros novos em Campinas que tenham obras residenciais em andamento;

- Identificar e caracterizar os locais de deposição de RCD na cidade de Campinas;

- Analisar quantitativamente e qualitativamente os RCD gerados nesses tipos de obras de residência padrão normal (até $106,44 \mathrm{~m}^{2}$ de área real).

Diante do cenário exposto, este projeto tem como objetivo analisar a geração de Resíduos de Construção e Demolição (RCD) oriundos de construções de casa de padrão normal, segundo a NBR n $12.721-2004$, na cidade de Campinas.

\section{METODOLOGIA}

Esse trabalho é um estudo descritivo que abrange aspectos gerais e amplos que reflete um contexto social (OLIVEIRA 1999). Tem uma abordagem qualitativa cujo objetivo é analisar os resíduos sólidos da construção e demolição (RCD) advindos de construções de padrão normal. Para a coleta de dados e observações dos fatos, a pesquisa se classifica como de campo possibilitando o estabelecimento de relações constates entre determinadas condições.

A coleta de dados foi feita nas visitações aos locais sendo fontes primárias e em pesquisas na internet com fontes secundárias, buscando sempre o maior aproveitamento para um melhor resultado final.

\section{Instrumentos}


Para a coleta de dados foram realizadas visitas semanais nos três locais de obra escolhidos. Em cada visitação foram realizadas observações e o preenchimento de um formulário baseado na observação, com os dados coletados, elaborado exclusivamente para esta pesquisa. Além disso foram feitas algumas capturas de imagens facilitando a análise futura dos dados. Recursos tecnológicos também foram utilizados para registrar fatos ocorridos e a situação do local tais como celular e câmera digital.

O formulário é composto por uma parte onde é registrada a identificação da obra em analise, com as seguintes informações: bairro e a data da visita. Em seguida foi necessária indicar em qual etapa está a construção: Infraestrutura, Alvenaria/Vedação, Cobertura, Instalação hidráulica, Instalação elétrica ou Acabamento, sendo que tal classificação será usada posteriormente para a análise dos dados. Existe também, um campo para registro de observações e anotações, usado para descrever o que foi verificado na visita. Por fim existe uma tabela onde são registrados todos os resíduos encontrados e quantidade em porcentagem de cada um, caso não seja encontrado nenhum existem um campo para preenchimento.

\section{Visita técnica à URM}

Em 13/03/2017 foi realizada uma visita técnica na U.R.M. (Usina recicladora de materiais) a fim de analisar seu funcionamento, qual resíduos eram recebidos e o que era feito com cada um deles. A Unidade Recicladora de Materiais (URM), implantada em 2003, em local público, visa o tratamento de resíduos da demolição e da construção civil de toda a cidade de Campinas. Desde abril de 2007 é gerenciado pelo Departamento de Limpeza Urbana-DLU, que organiza as atividades necessárias para o funcionamento ideal da unidade. (Prefeitura de Campinas).

Antes de 2007 a unidade recebia qualquer tipo de resíduo e simplesmente juntavam tudo em grandes pilhas sem que fosse realizada a correta classificação. Porém, após a mudança de gestão e a troca da supervisão da U.R.M. por uma engenheira ambiental, os resíduos começaram a ser controlados e passaram a ser melhor reaproveitados. O processo todo passou a ser mais controlado e monitorado.

A usina trabalha com base no decreto $\mathrm{n}^{\circ} 18.167$ de 29 de novembro de 2013 que regulamenta a lei 14.418, instituindo na cidade o Plano Integrado de Gerenciamento de Resíduos da Construção Civil. Este decreto especifica todos os resíduos da construção civil gerados na cidade de Campinas e o que deve ser feito com ele. Além disso consta nele todas as documentações e fichas para o preenchimento das empresas geradoras de RCC. Cada empresa transportadora deve fazer um cadastro e preencher uma ficha de controle de transporte de resíduos (CTR) para cada caminhão que descarrega na usina.

Por ser gerenciado pelo DLU, tudo que é produzido na U.R.M. é destinado para uso das obras feitas pela prefeitura. A maioria dessas obras é de recapeamento e recuperação de topografias em ruas não pavimentadas. A usina conta com um triturador que transforma $o$ entulho em alguns tipos de brita e em areia.

Atualmente o processo da usina consiste em algumas etapas. Primeiramente a empresa transportadora deve fazer um cadastro junto a prefeitura para ter autorização para descartar os resíduos na U.R.M., assim que o cadastro é autorizado a empresa está liberada para levar suas caçambas até o local. No dia da visita o valor cobrado por $\mathrm{m}^{3}$ de resíduo era de $\mathrm{R} \$ 13,47$, considerando que em média, cada caçamba tem um volume de $5 \mathrm{~m}^{3} \mathrm{o}$ valor por caçamba é de $\mathrm{R} \$ 67,35$. Futuramente, quando for concluída a instalação de uma balança, será cobrado por peso.

Cada caminhão que chega deve apresentar uma CTR referente a caçamba que será descarregada contendo a descrição do RCC presente nela. Após uma aferição da CTR o caminhão é encaminhado para um determinado local na usina. Quando chega um tipo de 
resíduo especifico como gesso ou madeira, existe um lugar determinado onde é armazenado esse material, porém quando é trazido tudo misturados, os resíduos são despejados em um monte para ser triturados e separados. Na hora do despejo, caso seja encontrado algum resíduo tóxico como o amianto e tintas, ou algum material que não está descrito na CTR, o mesmo é carregado novamente na caçamba para que o transportador dê um outro destino.

A grande parte das caçambas, são descarregadas com materiais diversos misturados e o mesmo são colocados em um monte para serem triturados (Figura 2).

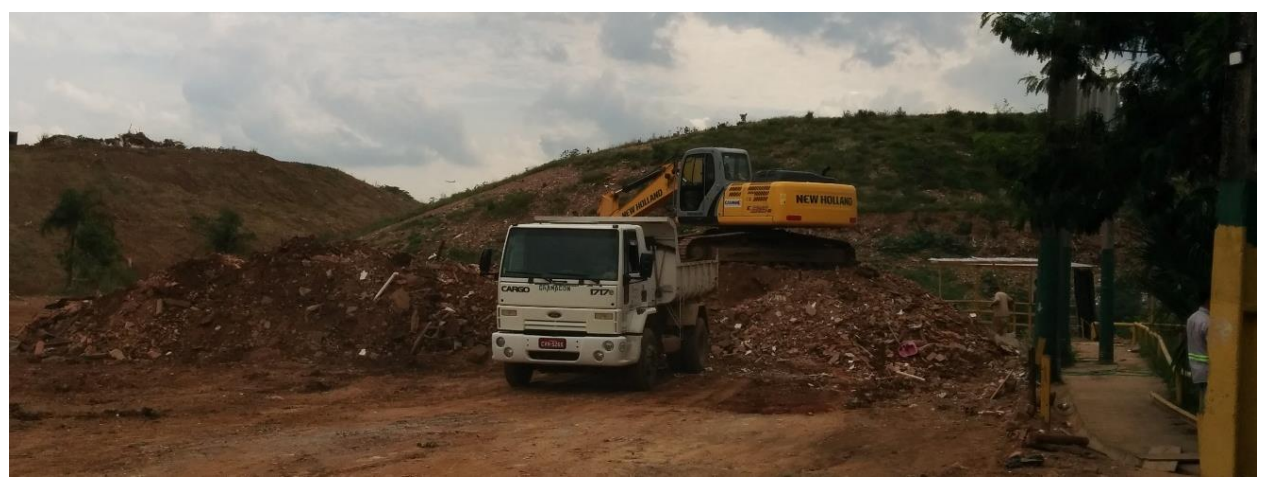

Figura 2 - Foto do Início do processo de trituração dos resíduos, Unidade recicladora de materiais, Campinas, São Paulo (2255'28.1"S 4708'40.1"W; -22.924477, -47.144465)

(Fonte: Próprio autor (2017))

Quando o acumulo é grande o triturador é ligado. A retroescavadeira transfere os materiais do monte para entrada da máquina de triturar. Nesse primeiro momento há uma separação mais superficial. Um funcionário remove alguns itens mais fáceis de serem separados e os separa, porém, a grande parte entra no triturador. Existe também um operador que controla a máquina, ligando e desligando conforme os resíduos são transferidos. $\mathrm{Na}$ entrada do triturador há uma peneira que permite a passagem de alguns pedaços de materiais mais pequenos, esses pedaços menores caem em uma esteira e são levados para um monte diferente pois os agregados com granulometria menores têm funções diferente daqueles mais grossos. Assim que os materiais passam pelo motor principal, os pedaços caem em uma esteira. Ao longo dessa esteira ficam algumas pessoas recolhendo material que não servem para virar brita, como por exemplo: ferro, resíduo orgânico, tecido, madeira, tubos de pvc entre outros (Figura 3).

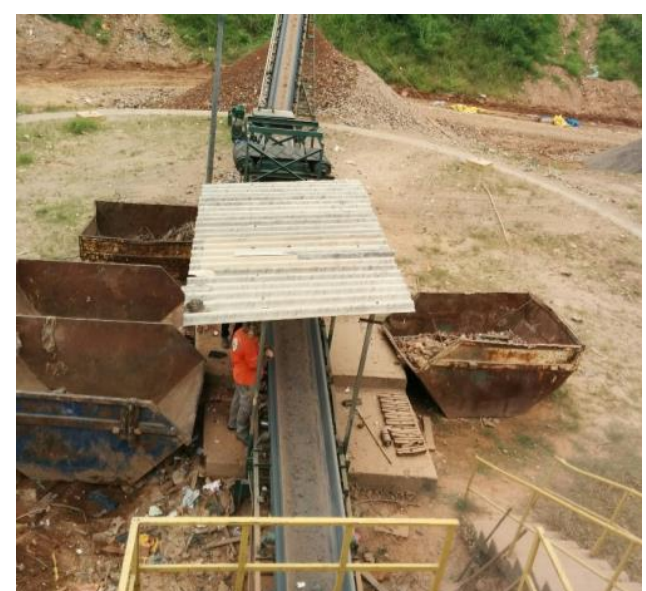

Figura 3 - Foto do processo de separação pós trituração, Unidade recicladora de materiais, Campinas, São Paulo (2255'28.1"S 4708'40.1"W; -22.924477, -47.144465) (Fonte: Próprio autor (2017)) 
Ao final o que sobrou é despejado em uma pilha de pedras. Esse é a matéria prima que a prefeitura usa para as obras na cidade. Essas britas ficam na usina até serem retiradas pelos caminhões para serem utilizados nas obras de melhoria da cidade de Campinas.

A U.R.M. trabalha de acordo com a demanda do departamento de limpeza e urbanização. No dia da visita eles estavam atendendo ao pedido feito pela prefeitura. Porém quando não há demanda ou é muito baixa, então é feita uma separação de material e de brita. Materiais compostos de concreto e argamassa são chamados de Cinza, já os materiais compostos de cerâmica são chamados de Vermelho. Entre os dois tipos, o material cinza é tem a maior resistência e consistência por, por causa disso o material cinza é triturado e transportado para uma peneira, que por sua vez separa os agregados em brita 2, brita 1 , brita 0 e areia (Figura 9). Após separados essas britas são usadas para construções na própria usina. O prédio administrativo foi construído usando agrados produzidos pela usina.

Dentro da U.R.M. tem uma parte destinada à uma cooperativa de reciclagem chamada Tatuapé. Todo material que é separado no processo e que pode ser reciclado, é coletado pelos funcionários da cooperativa, que por sua vez vendem estes materiais e desta forma geram renda para sobreviverem. Além do que é coletado do RCC a prefeitura entrega uma quantidade de resíduos recicláveis para ajudar a cooperativa. No dia da visita foi registrado uma imagem (Figura 4) do local onde os funcionários deixam os resíduos separados para vender.

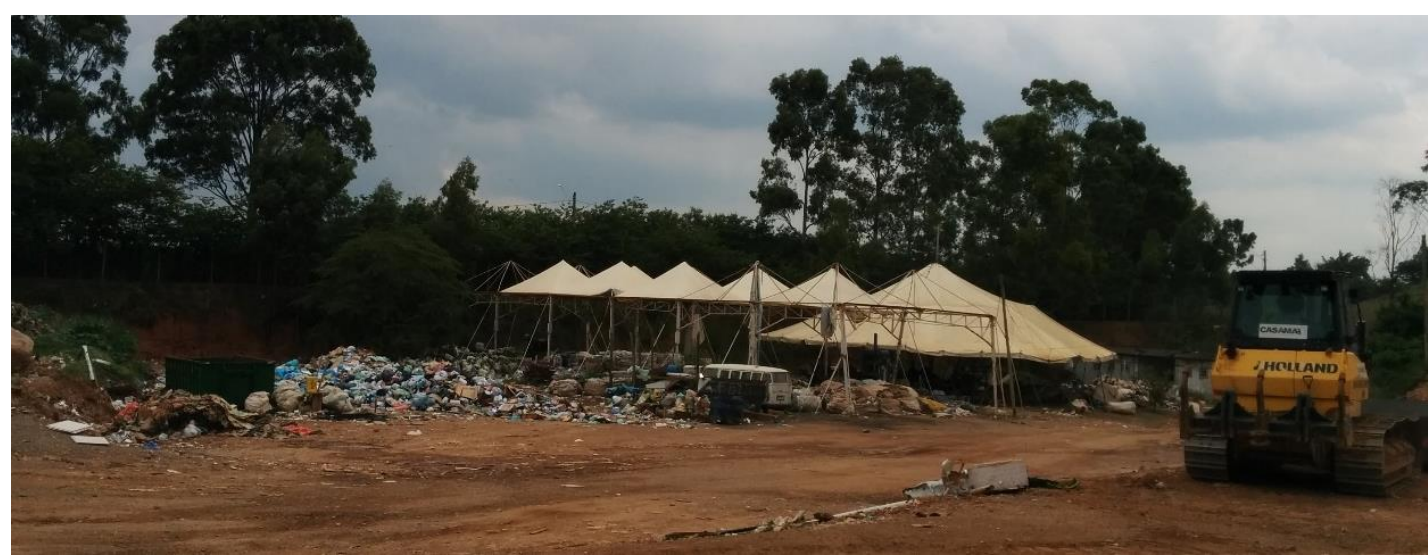

Figura 4 - Foto dos - Resíduos recicláveis separados pela cooperativa Tatuapé, Unidade recicladora de materiais, Campinas, São Paulo (22 55'28.1"S 4708'40.1"W; -22.924477, 47.144465) (Fonte Próprio autor (2017))

\section{RESULTADOS E DISCUSSÃO}

Para análise dos resultados, foi elaborado uma tabela para cada uma das obras contendo o dia da visita na primeira coluna, a etapa atual da obra na segunda coluna (uma obra pode estar em mais de uma etapa) e nas colunas subsequentes estão todos os materiais e a porcentagem de cada um baseado em um total de $100 \%$ em cada visita. As tabelas foram alimentadas após todas as visitas feitas.

Baseado nos dados da tabela foi possível criar um gráfico (figura 5) com a porcentagem geral dos resíduos encontrados em cada local de obras. 


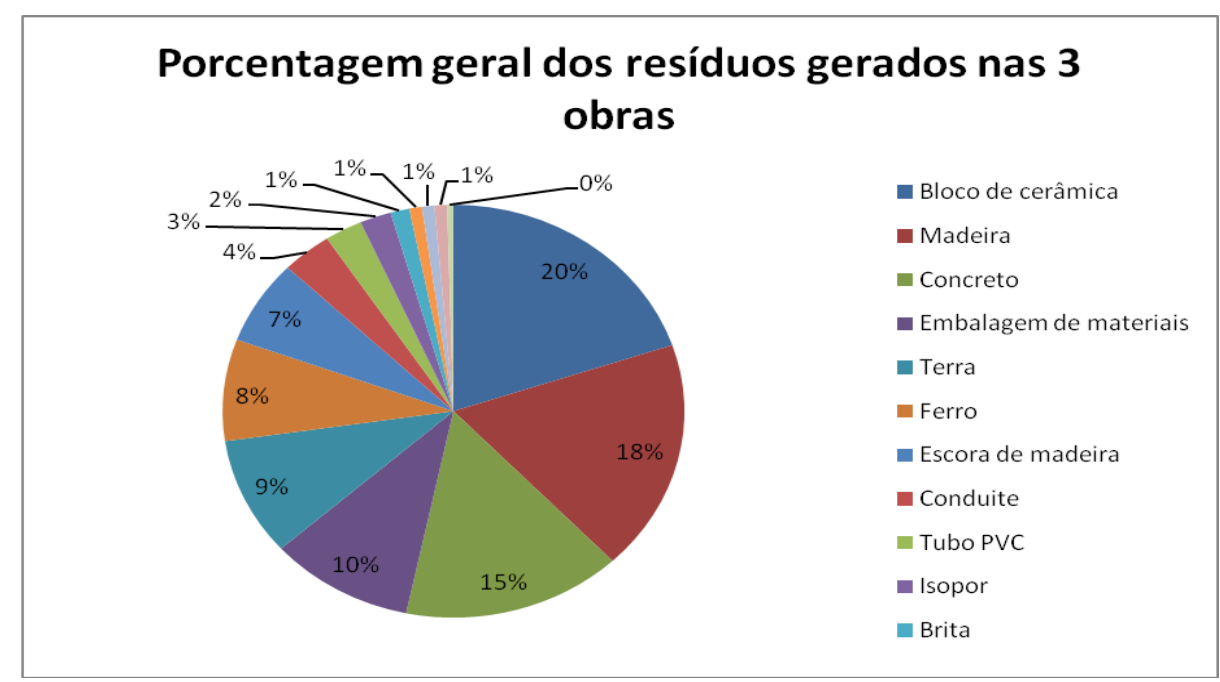

Figura 5 - Porcentagem geral de resíduos gerados nas 3 obras (Fonte: Próprio autor (2017))

Considerando o critério usado para a análise feita que dividiu a obra em seis etapas, pôde-se analisar diferentes tipos resíduos que só são gerados em determinada fase de uma construção. Sabendo quais são os principais resíduos gerados em cada etapa fica mais fácil encontrar meios para dar o devido destino ou conseguir reciclar e até mesmo reutilizá-lo.

Até o dia 12/03/2017 (última visita registrada) foram realizadas vinte e cinco visitações aos canteiros de obras. Infelizmente no dia 06/11/2016 a obra da casa $n^{\circ} 10$ localizada no bairro parque fazenda foi totalmente fechada, dificultado o levantamento dos dados. Então a partir desta data não foram realizadas mais visitações a esta obra, porém os dados coletados anteriormente serão mantido e foram considerados nas análises. A seguir estão as imagens na figura 6,7 e 8, de cada residência em seu estágio atual.

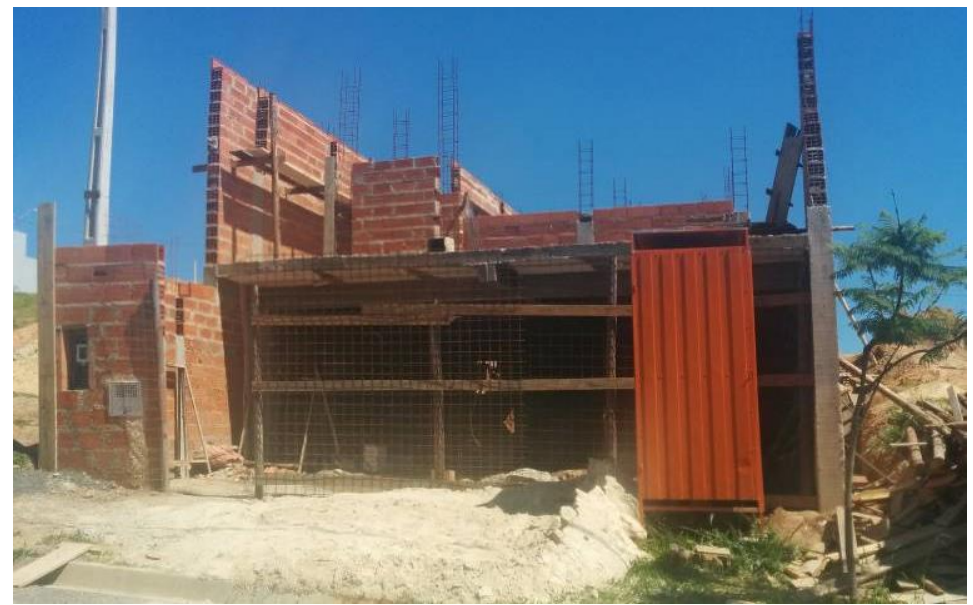

Figura 6 - Foto da casa $\mathrm{N}^{\circ} 111$ no Jardim Ibirapuera - 20/11/2016 (2255'06.7"S $47^{\circ} 07^{\prime} 04.2^{\prime \prime W}$; -22.918529, -47.117833) (Fonte: Próprio autor (2016)) 


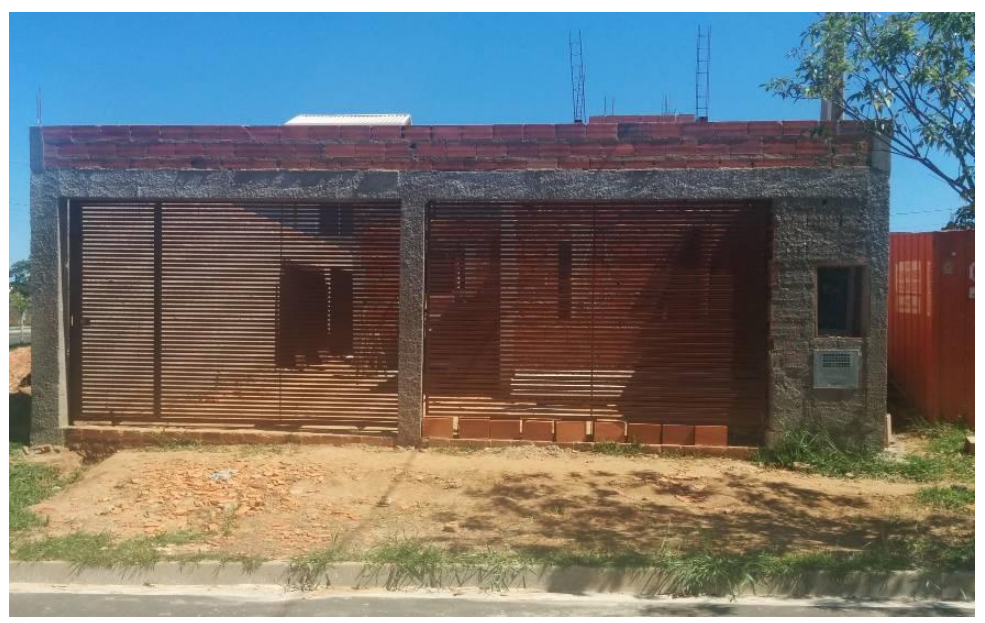

Figura - Foto da casa $\mathrm{N}^{\circ} 15$ no Jardim Ibirapuera - 20/11/2016 (22 ${ }^{\circ} 54 ' 52.2 " \mathrm{~S}$ 4707'02.2"W; -22.914492, -47.117277) (Fonte: Próprio autor (2016))

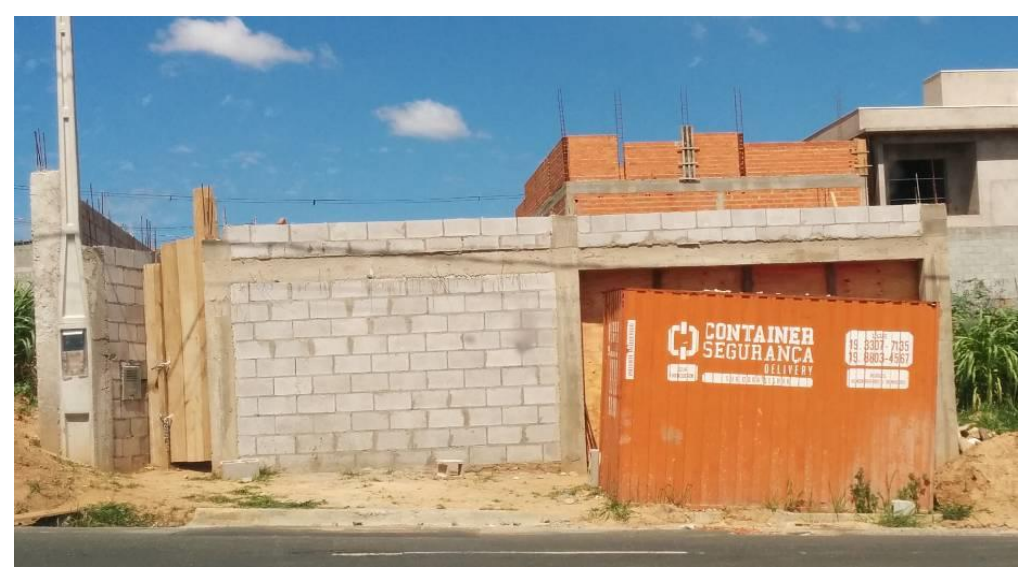

Figura 8 - Foto da casa No 10 no Parque Fazenda - 06/11/2016 (2255'48.4"S 4707'06.2"W; -22.930107, -47.118397) (Fonte: Próprio autor (2016))

Terra

A grande maioria dos terrenos escolhidos para construção de uma residência são irregulares e por causa disso é necessário fazer terraplenagem antes de começar a construção da casa. Dependendo da cota do projeto pode ser feito dois procedimentos: corte (tirar terra do terreno) e/ou aterro (colocar terra no terreno).

Em algumas situações, que hajam os dois processos, é possível usar a terra retirada na escavação para fazer o aterro. Existem obras que se consegue aproveitar o material todo na própria obra, porém essa não é ocorrência mais comum. Nos dois casos analisados a terra acabou se tornando resíduos pois não pôde ser utilizada no terreno, uma vez que ele já era pouco irregular (Casa 15 e 10) ou os processos de escavação tirou terra mais que suficiente (Casa 111).

Uma atitude cordial e até sustentável para obras que apresentam um excedente de terra, seria fazer uma doação para outras obras que precisam importar esse recurso. Desse modo o resíduo não será descartado e estará ajudando a baratear o custo de outra construção, uma vez que a terraplenagem pode representar até $20 \%$ segundo empresas do ramo.

Outro ótimo meio de utilizar a terra vermelha, é fazer áreas verdes no quintal. Construir um jardim além de ser uma atitude sustentável, pode ter várias vantagens tais como: cultivo de frutas e vegetais para consumo próprio e diminuição de gasto com comida, tornar o 
ambiente mais agradável e também contribuir para infiltração da agua da chuva no solo, diminuindo assim o risco de pequenos alagamentos na residência.

\section{Madeira}

Quando falamos de madeira é relevante salientar que este é um recurso natural do planeta e que muitas vezes é obtido de forma ilegal e sem qualquer preocupação com o meio ambiente. É extremamente importante se conscientizar e usar somente madeiras legalizadas ou de reflorestamento vendidas por empresas certificadas e confiáveis.

Considerando este material apontado pela coleta de dados como um dos principais resíduos gerados na etapa de infraestrutura é evidente que alguma coisa deve ser feita com esse desperdício. Atualmente grande parte já é destinada para reciclagem, onde, dependendo do tipo de madeira e do estado em que se encontra o material, pode virar outros tipos de consumível. A Revista da Madeira edição $n^{\circ} 77$ (2003) elencou algumas das alternativas de destinação para os resíduos de madeira:

- Compostagem: utilizando dos restos vegetais através do processo de compostagem, os restos são amontoados, irrigados e revolvidos, acelerando o processo de decomposição para utilização em fertilizantes naturais.

- Resíduos estruturantes: com a serragem fina retirada da madeira é possível acelerar a biodegrabilidade do lodo de esgoto nas estações de tratamento.

- Produção de energia: serve como matéria prima para usinas de Biomassa que aproveitam a energia já existente no material para gerar energia elétrica.

- Lenha: além de ser usadas nas usinas de biomassa a madeira também é usada como lenha em diversos estabelecimentos que tem fornos e também em casas com lareiras.

- Combustível: matéria prima para produção de gases combustíveis e combustíveis líquidos através de processos como gaseificação, liquefação e hidrólise.

- Carvão vegetal: não é uma alternativa sustentável, porém ainda é opção para fornos de alvenaria conhecido como "medas" e "caieras".

- Produção de painéis: para fabricação dos painéis as partículas de madeira são aglomeradas com outros materiais, e por meio de uma resina especial tudo fica aglutinado para ser prensado e virarem chapas.

- Produção de briquetes: a briquetagem é o processo de compactação de resíduos, onde é destruída a elasticidade natural das fibras. Este processo diminui o consumo de energia para queima, resultando em um material com pequeno volume, alta densidade e com alto poder calorífico.

- Produção de Papel: esse é um método mais comum em alguns países onde há escassez de recurso natural e então utilizado resíduos de madeira para confecção de papeis.

- Farinha de madeira: Obtida pelo processo de moagem das diversas aparas de madeira, e usada como matéria-prima para gerar produtos acabados ou semiacabados, para indústrias de plásticos, de fundição, de compensados, de explosivos ou de calçados.

Outra forma de aproveitar o material é usar como objeto decorativo, seja nas paredes ou então em peças de artesanato. Existem algumas boas ideias de uso para montagem de jardim vertical mostrado na figura 9, uma forma de reaproveitar o resíduo e ajudar o meio ambiente com o plantio de plantas e vegetais. 


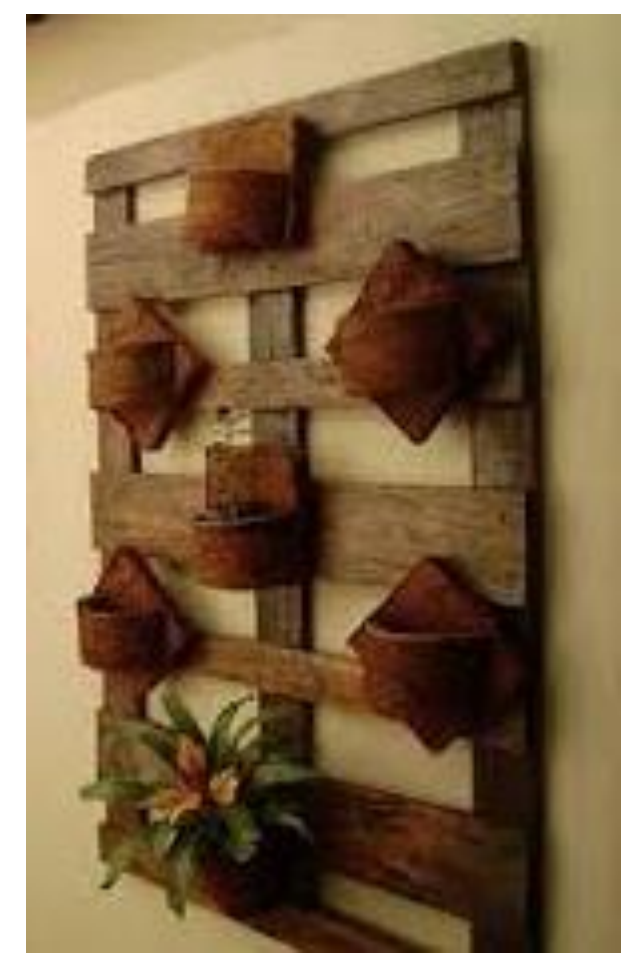

Figura 9 - Foto de um exemplo de Jardim vertical com madeira de demolição (Fonte: GOOGLE IMAGENS)

\section{Bloco de cerâmica}

Os blocos cerâmicos são obtidos através da queima da argila durante o processo de extrusão que muda de acordo com o formato do bloco e a aplicação que será feita. São usados na alvenaria de vedação e estrutural devido a sua alta resistência a esforços de compressão, isolamento térmico, resistência ao fogo, baixo peso e valor mais baixo comparado com blocos de outros materiais. Além disso é considerado um material sustentável pois pode ser reaproveitado.

No entanto o fato de ele ter uma grande resistência a compressão, o bloco de cerâmica acaba não aguentando outros esforços, tornando - o frágil. Essa fragilidade é um dos principais motivos pela alta incidência desse material nos resíduos encontrados nas obras analisadas. Por descuido, muitos blocos acabam quebrando e até mesmo trincando, impossibilitando sua utilização na obra.

No processo de fabricação do bloco e de outros materiais feitos de cerâmica quando ocorre a queima da matéria prima, a composição do material muda, atribuindo as características citadas anteriormente. No entanto não é possível fazer esse procedimento novamente assim como acontece com metais. O melhor meio de reutilizar a cerâmica é triturar os blocos em grãos de diferente granulométria para ser substituído por agregados do concreto como a areia e brita. Porém o uso da cerâmica britada implica diretamente na resistência do concreto, por isso é mais recomendando usá-lo para fazer bloco, contra-pisos, passeios e outros. Pode ser aplicado com argamassa de assentamento ou na forma de sub-base de calçamento, pavimentação, lastros em lagos, córregos e represas (SILVA E SANTOS, 2014).

Em algumas obras pode até ser interessante o aluguel de um triturador de entulho e usá-lo para conseguir, não só cerâmica, mas também com outros materiais, agregados para usar em argamassas e concreto. É uma forma de economizar na compra de matéria prima e aproveitar os resíduos já gerados. 


\section{Concreto}

Hoje não existe uma obra que não use concreto. É um material que tem diversas aplicações, seja na parte estrutural quanto na parte de alvenaria. Consequentemente uma grande porção dos resíduos da construção, acaba sendo pedaços de concreto já endurecidos. Existem alguns meios de reaproveitar esse concreto após alguns procedimentos, parecido com os itens de cerâmica, e dessa forma economizar na compra de agregados para fabricação de outros concretos.

Para reaproveitar o concreto primeiramente é feito a quebra dos pedaços grandes em menores que variam de 75 a $120 \mathrm{~cm}$. Esses pedaços devem ser separados dos outros resíduos. A próxima etapa é triturar os pedaços para que se tornem grãos, com dimensão um pouco maiores que os da areia, e em sua maioria substituem a brita usada na fabricação do concreto convencional. Finalizado este procedimento já pode ser usado na fabricação de um concreto novo, em alguns casos esse material atinge uma alta resistência e pode ser usado em estruturas.

No Brasil a aplicação mais comum do concreto reciclado ocorre em sub-base de pavimentos, de concreto ou asfalto. No entanto, quando são atingidas as propriedades especificadas, a utilização pode acontecer em qualquer situação. (CIOCCHI, 2003). Há a possibilidade também de usar esse agregado em argamassas, porém é recomendado não deixar os componentes reciclados expostos a água.

Uma alternativa que poderia ser viável seria a locação de pequenos trituradores que poderiam ser usados na própria obra. Os materiais cerâmicos e os compostos por concreto e argamassa, depois de triturados podem substituir os agregados graúdos e miúdos de misturas novas. Com a separação certa o aproveitamento seria muito grande, reduzindo custo na compra de matéria prima nova, além de estar contribuindo com o meio ambiente.

\section{Embalagem de materiais}

Este foi um outro item bastante encontrado nos RCC das obras analisadas. A grande parte das embalagens encontradas foram de cimentos. As embalagens são feitas de papel Kraft, ele é um tipo de papel produzido a partir de uma mistura de fibras de celulose curtas e longas, provenientes de polpas de madeiras macias. Essa mistura atribui a este tipo de papel uma boa resistência mecânica e uma boa maciez. Vários fabricantes vendem sacos com $50 \mathrm{~kg}$, sendo necessário o uso desse material nas embalagens.

Atualmente existem diversas maneiras de reciclar e reaproveitar qualquer tipo de papel e não seria diferente com o kraft. Devido a suas características diferenciadas, alguns recicladores utilizam-no para fazer caixas, capas de caderno e vários outros itens de artesanato. O processo utilizado é bastante simples, depois de ser separado, lavado e triturado, ele é colocado em um molde e vai para secagem, após secar o papel pode ser moldado. A figura 10 mostra uma caixa feita com o papel reciclado.

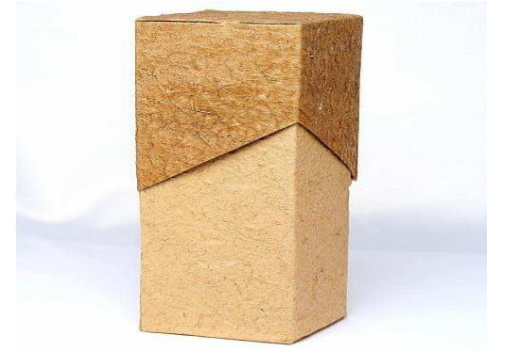

Figura 10 - Exemplo de uma Caixa de papel kraft reciclado (Fonte: INSTITUTO INDESE) 
Marcio Buson, professor na Universidade de Brasília, desenvolveu um projeto que utiliza este mesmo papel para fazer um tijolo ecologicamente correto que não contamina o solo e o lençol freático. Buson criou um bloco compactado composto por terra, cimento e o papel kraft.

\section{CONCLUSÕES}

Durante a pesquisa de campo, poucas foram as semanas em que não foi encontrado nenhum tipo de resíduo. O estudo foi feito baseado em obras residências, onde o consumo de material é menor, porém ainda sim muita coisa é descartada.

A pesquisa mostrou que pouco mais de $50 \%$ dos resíduos gerados só compostos apenas por três tipos: cerâmica, madeira e concreto, evidenciando que esses são os materiais que mais precisam de alternativas para serem melhor reutilizados.

Já existem vários destinos sustentáveis possíveis, basta as empresas e a sociedade como um todo ter consciência e dar a devida destinação. Se as entidades públicas investirem mais em instituições como a U.R.M. é possível criar um novo meio de gerar capital para a prefeitura além de ajudar o meio ambiente.

As pessoas ainda não se deram conta do estrago que os resíduos fazem ao meio ambiente pois ainda há recurso abundante e lugar para despejar toda essa matéria, porém uma hora isso vai acabar e as pessoas irão sentir o impacto desses atos. As empresas de construção civil também precisam investir bastante nesse setor, pois futuramente a empresa que souber reaproveitar seus resíduos sairá na frente das concorrentes e com certeza sobreviverá mais tempo no mercado.

A sociedade está caminhando para um mundo que precisará ser $100 \%$ sustentável, porém só depende do ser humano acelerar esse processo para que a vida no planeta possa perdurar por muitos e muitos anos.

\section{REFERÊNCIAS}

AGOPYAN, V. Construção Civil consome até $75 \%$ da matéria-prima do planeta. In: Globo Ciência. 2013. Disponível em: 〈http://glo.bo/12yaSCY〉. Acesso em 01 de setembro de 2015.

ASSOCIAÇÃO BRASILEIRA PARA RECICLAGEM DE RESÍDUOS DA CONSTRUÇÃO CIVIL E DEMOLIÇÃO. O que é entulho. 2015. Disponível em: <

http://www.abrecon.org.br/Conteudo/5/O-que-e.aspx>. Acesso em 17 de setembro de 2015.

ÂNGULO, S. C.; ZORDAN, S. E.; JOHN, V. M. Desenvolvimento sustentável e a reciclagem de resíduos na construção civil. PCC - Departamento Engenharia de Construção Civil da Escola Politécnica. São Paulo SP, 2010.

CONSELHO NACIONAL DO MEIO AMBIENTE - CONAMA: Resolução no. $\mathbf{3 0 7}$, de 05 de julho de 2002. Estabelece diretrizes, critérios e procedimentos para a gestão dos resíduos da construção civil. Diário Oficial da União, Brasília, DF, 17 de julho de 2002. Disponível em:< http://www.mma.gov.br/estruturas/a3p/_arquivos/36_09102008030504.pdf> - Acesso em 18 de ago 2015.

CSILLAG, D.. Análise das práticas de sustentabilidade em projetos de construção latino americanos. São Paulo, 2007, p.117. 
ESPINELLI, U. A gestão do consumo de materiais como instrumento para a redução da geração de resíduos nos canteiros de obras. In: seminário de gestão e reciclagem de resíduos da construção e demolição - avanços e desafios, 2005, São Paulo. Anais... São Paulo: PCC USP, 2005. 1 CD-ROM.

KIBERT, C.J.. Proceedings of the First International Conference on Sustainable Construction, Tampa, Florida, 6-9 November, 1994.

KIBERT, C. J.. Sustainable Construction: Green building Design and Delivery., 2nd Edition, New York: John Wiley \& Sons, Inc., 2008.

LARSSON, N.. An overview of Grren Building Rating System and Labeling Systems. In: I Conferência Lation Americana de Construcción Sostenible claSC'04, Entac 04. São Paulo - Brasil: [s.n], 2004.

OLIVEIRA, P. E. S.de; OLIVEIRA, J. T. R. de; FERREIRA, S R. de M. Avaliação do Desempenho do Concreto com uso de Agregados de Resíduos de Construção e Demolição - RCD: Publicação de Resumo nos anais do $50^{\circ}$ Congresso Brasileiro do Concreto- IBRACON - CBC 2008; Salvador - BA.

PINHEIRO, M. D.. Ambiente e construção sustentável. Instituto do Ambiente, 2006.

ROCHA, M. P. da.. Proposta de indicadores de sustentabilidade na gestão de resíduos de construção e demolição. Dissertação (Mestrado) - Universidade do Porto. Faculdade de Engenharia, 106p., 2012.

SANTOS, T. J. de S.; SOARES NETO, J. P.. Identificação de aspectos ambientais e seus respectivos impactos em construção civil. Gestão ambiental para a indústria da construção civil do Tocantins: manual de referência. Palmas, TO: SESI - SINDUSCON DR/TO, 61p., 2008.

SELIH, J. Envionmental management systems and constrution SME: a case study for Slovenia. Civil Engineering and Management, v.13, n.3, September 2007, p.217-226p. 